\title{
The Verona diabetes study: a population-based survey on known diabetes mellitus prevalence and 5-year all-cause mortality*
}

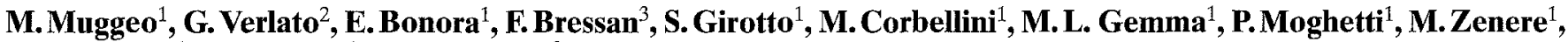 \\ V. Cacciatori ${ }^{1}$, G.Zoppini ${ }^{1}$, R. De Marco $^{2}$ \\ ${ }^{1}$ Institute of Metabolic Diseases, University of Verona, Verona, Italy \\ ${ }^{2}$ Institute of Medical Statistics, University of Verona, Verona, Italy \\ ${ }^{3}$ Institute of Statistics, University of Verona, Verona, Italy
}

\begin{abstract}
Summary This population-based survey aimed to determine the prevalence of known diabetes mellitus on 31 December 1986, and to assess all-cause mortality in the subsequent 5 years (1987-1991) in Verona, Italy. In the study of prevalence, 5996 patients were identified by three independent sources: family physicians, diabetes clinics, and drug prescriptions for diabetes. Mortality was assessed by matching all death certificates of Verona in 1987-1991 with the diabetic cohort. Overall diabetes prevalence was $2.61 \%$ (95\% confidence interval 2.56-2.67). Prevalence of insulin-dependent and non-insulin-dependent diabetes mellitus was $0.069 \%(0.059-0.078)$ and $2.49 \%$ (2.43-2.54), respectively. Diabetes prevalence sharply increased after age 35 years up to age 75-79, and finally declined. Prevalence was higher in men up to age 69 years, in women after age 75 years. Of the diabetic cohort 1260 patients (592 men, 668 women) died by 31 December 1991, yielding an overall standardized mortality ratio of 1.46 (CI 1.38-1.54). Even though the differences narrowed with age, mor-
\end{abstract}

tality rates in the diabetic cohort were higher than in the non-diabetic population at all ages. Women aged 65-74 years showed observed/expected ratio higher than men $(2.27$, CI 1.92-2.66, vs 1.50, CI 1.30-1.72), while in other age groups the sex-related differences were not significant. Pharmacological treatment of diabetes was associated with an excess mortality, while treatment with diet alone showed an apparent protective effect on mortality (observed/expected ratio 0.73 , CI 0.58-0.92). In conclusion, in Verona diabetes has a prevalence similar to that of other European countries, and is associated with an excess mortality which is observed in both sexes, at all ages, and with any anti-diabetic pharmacologic treatment. Diet-treated diabetes seems to be associated with a significant reduction in the mortality risk. [Diabetologia (1995) 38: 318-325]

Key words Diabetes mellitus, epidemiology, mortality, population survey, therapy.
Received: 30 March 1994 and in revised form: 19 August 1994

Corresponding author: Professor M.Muggeo, Malattie del Metabolismo, Ospedale Civile Maggiore, Piazzale Stefani, 1 37126 Verona, Italy

Abbreviations: SHU, Social Health Unit; OHD, oral hypoglycaemic drugs; CI, confidence intervals; obs/exp, observed to expected ratio; SMR, standardized mortality ratio.

\footnotetext{
* Preliminary data on prevalence and on mortality have been presented at the annual meetings of the European Diabetes Epidemiology Study Group held at Dead Sea (Israel) in 1990, and in Cambridge (UK) in 1993 respectively.
}

For the majority of southern European countries data on the epidemiology of diabetes mellitus and related mortality are not conclusive. In this area, the overall diabetes prevalence has an apparently wide variability, ranging between 1 to $23 \%$, a difference reflecting methodological rather than geographical differences [1]. In Italy studies carried out using similar methodology recently reported that known diabetes prevalence ranges from $2.2-2.5 \%[2,3]$.

For diabetes mortality in southern Europe, the only available data are those derived from the World Health Annuals Statistics [4]. However, such information should be interpreted with caution, as it is derived from the reporting of diabetes on death certifi- 
cates. This method is not reliable in the assessment of diabetes-related mortality, since it generally leads to an underestimation of the phenomenon $[5,6]$. In southern Europe population-based prospective studies on diabetes-related mortality are lacking.

The aim of the present study was to determine the prevalence of known diabetes and to assess diabetesrelated 5-year all-cause mortality in Verona, a midsize town of north-east Italy.

\section{Subjects and methods}

Study design and rationale. This study, named the Verona Diabetes Study, was designed to ascertain all known diabetes cases in the area of Verona, by using three independent sources: family physicians, diabetes clinics, and a database of prescriptions for antidiabetic drugs and diagnostic and therapeutic devices.

The rationale on which the study is based is that an accurate estimate of prevalence of known diabetes can be assessed only by using simultaneously more than one source for identification of diabetic subjects $[2,3]$.

Area of investigation and relative diabetes care. The area where the Verona Diabetes Study was carried out corresponds to the Social Health Unit of Verona (Verona SHU). The population of this area consisted of 301,519 inhabitants on 31 December 1986.

In this area diabetes care is provided by two diabetes clinics, one for adults, and one for people younger than 18 years (Juvenile Diabetes Centre). All patients with diabetes onset prior to the age of 18 years are registered at and followed-up by the Juvenile Diabetes Centre. Older patients attend the diabetes clinic for adults, refer to a family physician, or both. In Italy each citizen is assigned by law to a family physician or paediatrician of the SHU, which is part of the National Health System. On 31 December 1986 the family physicians and paediatricians in the Verona SHU numbered 298. Of these 220 $(78 \%)$ agreed to take part in this study.

In Italy, as long as the prescriptions are made by family physicians or paediatricians, or by the diabetes clinics of the SHU, anti-diabetic drugs (insulin, sulfonylureas, biguanides and associated drugs), and diagnostic and therapeutic devices (strips, glucose meters, insulin syringes, insulin pumps) are provided to the patients free of charge. In the Verona SHU, all prescriptions are recorded in a computerized system, which allows identification of all consumers of anti-diabetic drugs and diagnostic and therapeutic devices.

Target population. For the prevalence study, we considered all inhabitants of the SHU of Verona who were in charge to the 220 family physicians and paediatricians collaborating in the Verona Diabetes Study on 31 December 1986. Therefore, 244,575 inhabitants ( $81.1 \%$ of the total population) were considered as the target population.

The sex-structure of the target population was virtually identical to that of the general population of Verona SHU. The male to female ratio was 0.907 in the general population and 0.908 in the target population. Due to the complete participation of paediatricians in the study, the age-structure of the target population was slightly different from that of the general population. Subjects aged under 20 years represented $22.8 \%$ of the general population but $28.1 \%$ of the target population.
Case identification. As stated, diabetic patients were identified from three different sources:

1) Family physicians and paediatricians, who were considered the primary source. Co-operating physicians and paediatricians were preliminarily reminded of the National Diabetes Data Group criteria for diabetes diagnosis [7], and were asked to complete a form on all the diabetic patients in their care on 31 December 1986.

2) The records of all patients under the care of the two diabetes clinics of the Verona SHU on 31 December 1986. Among these patients, only those included in the target population were considered for the study.

3) The database of prescriptions for antidiabetic drugs and diagnostic and therapeutic devices made during 1986. From this database only patients included in the target population having more than two prescriptions for diabetes within 6 months, and alive on 31 December 1986 were considered for the study.

Any subject identified by any one of these three sources of information was considered a diabetic case. For each case, data on personal and family medical history, diabetes onset, and therapy were collected and a careful physical examination was carried out by the family physicians or by the physicians of the diabetes clinics. Patients were classified as insulin-dependent diabetic (IDDM) if they were under age 35 years at diagnosis and had started insulin treatment within 2 years after diagnosis, and non-insulin-dependent diabetic (NIDDM) if the diagnosis was made after age 35 years irrespective of treatment, or, irrespective of age at diagnosis, if treated with diet and/or oral hypoglycaemic drugs (OHD). In 115 cases it was impossible to obtain detailed information regarding onset of diabetes and past therapy. In these cases the diagnosis of "unclassified diabetes" was made.

Mortality assessment. The life status of the diabetic cohort identified on 31 December 1986 was ascertained on 31 December 1991. For this purpose:

1) All mortality records of the Verona SHU from 1 January 1987 to 31 December 1991 (about 18000) were carefully reviewed. Deaths from the diabetic cohort were identified on the basis of Social Health Code, name, date and place of birth. 2) A list of all people who moved away from Verona during the years 1987-1991 was obtained from the administrative database of the SHU of Verona. The list was checked to identify subjects included in the diabetic cohort followed-up for mortality, their new addresses were obtained, and their life status was ascertained by phone calls. Of the initial cohort 134 subjects $(2.2 \%)$ who had moved away from Verona during the follow-up period were not traced and for the statistical analysis were considered alive at the end of the follow-up.

Observed deaths were compared with expected deaths, using as a reference the non-diabetic population of the SHU of Verona. Sex- and age-specific mortality rates for all causes were obtained from the local Office of Statistics.

\section{Statistical analysis}

Results of continuous variables are reported as mean $\pm \mathrm{SD}$, while results of categorical variables are reported as percentage with $95 \%$ confidence interval (CI) in brackets. Prevalence of diabetes and of its different types were computed by the direct method of standardization, using the same age and sex distribution of the population of Verona SHU as the target population. Significance of differences between sexes was tested with the unpaired $t$-test for continuous variables and with the chi-square test for categorical variables. 


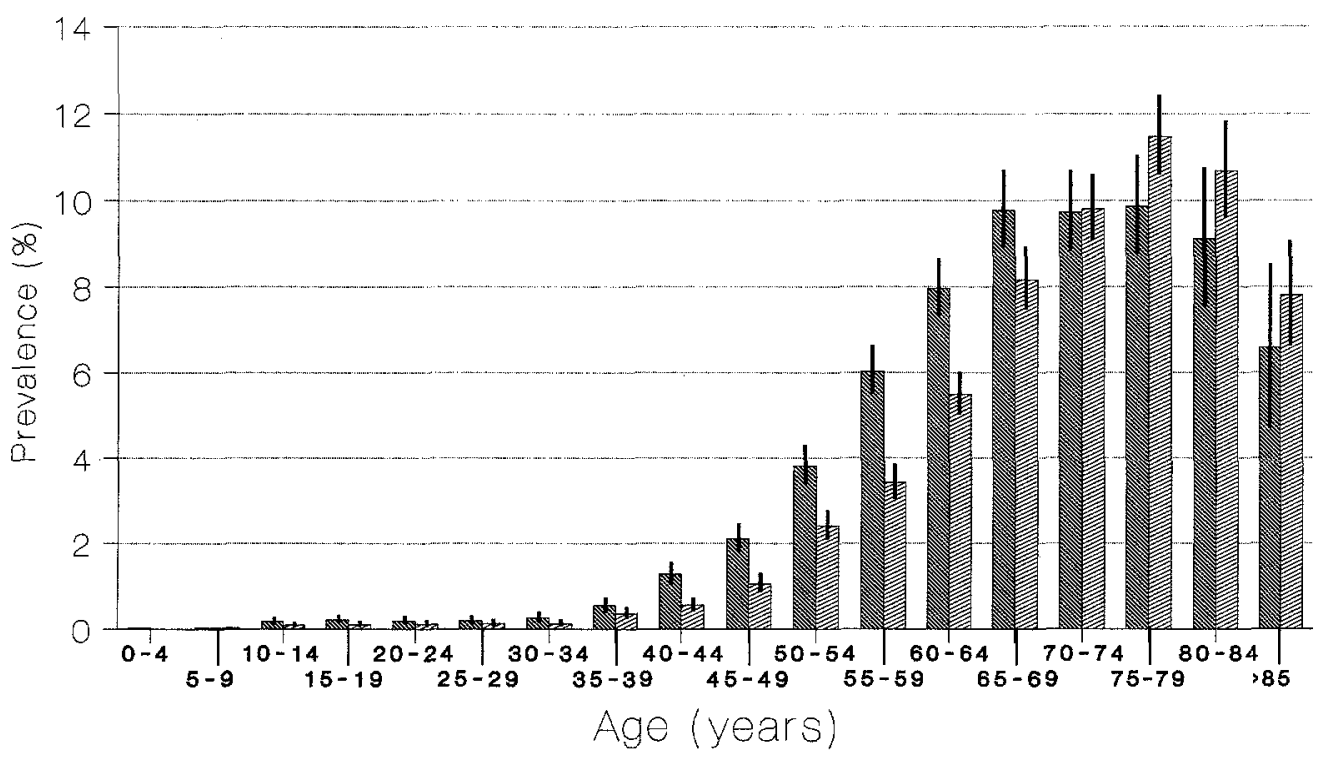

Fig. 1. Age-specific prevalence rates $(\%)$ of known diabetes mellitus in the Social Health Unit of Verona on 31 December 1986, in men (N) and women (埌)
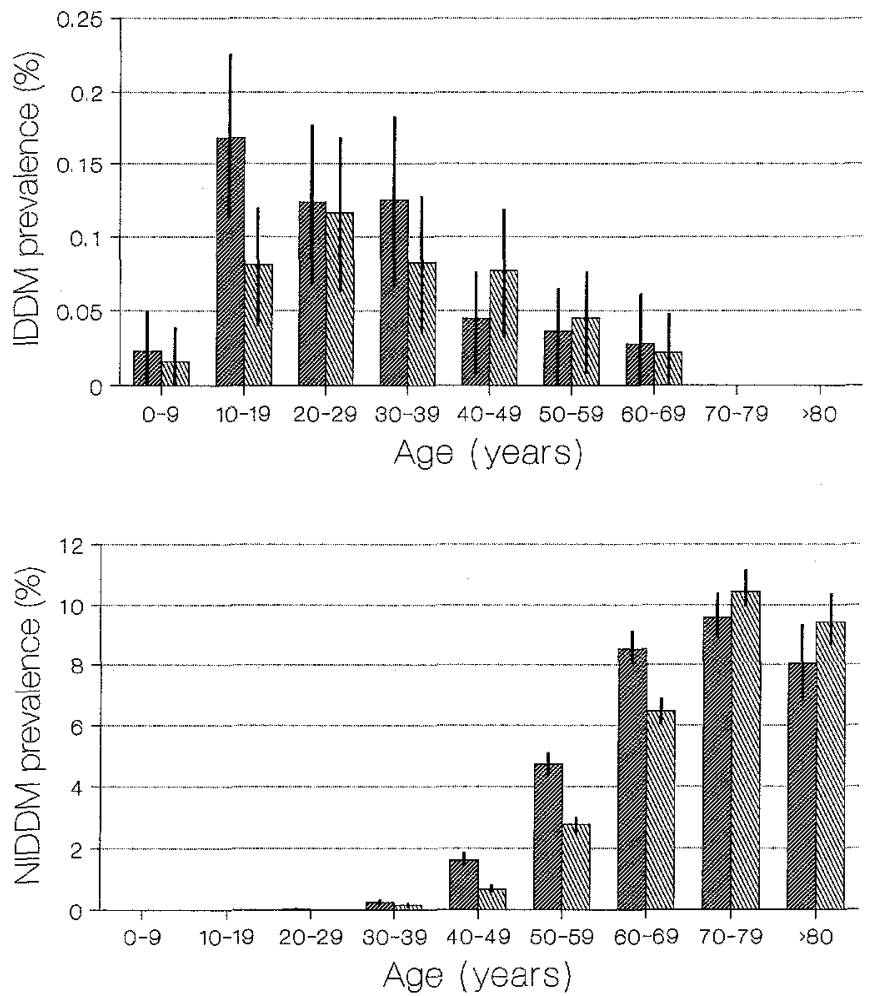

Fig. 2. Age-specific prevalence rates (\%) of IDDM and NIDDM in the Social Health Unit of Verona on 31 December 1986 , in men (\%) and women (WW)

Mortality rates and standardized mortality ratios (SMR) were computed by means of the program PYRS (personyears) version 1.3 [8]. Byar's approximation [9] was used to calculate $95 \% \mathrm{CI}$ for SMR. The changes in mortality risk were considered significant when the corresponding SMR CI did not include the unity. When necessary, significance of SMR was tested using the simple continuity corrected chi-square statistic [10]. Comparison of SMR and test for trend in the SMR (Poisson trend statistic) were performed according to Breslow and Day [9].

\section{Results}

Prevalence study. Using family physicians as a primary source 3,521 diabetic subjects $(58.7 \%)$ were identified, $1904(31.8 \%)$ by diabetes clinics as a secondary source, and $571(9.5 \%)$ solely from the prescriptions database (third source). A total of 5996 diabetic patients were identified in the target population. This resulted in an overall diabetes prevalence of $2.45 \%$ (CI 2.39-2.51). After adjusting for sex and age according to the population structure in the Verona SHU, prevalence amounted to $2.61 \%$ (CI 2.56$2.67)$. The prevalence was slightly higher in females $(2.63 \%$, CI $2.55-2.71)$ than males $(2.59 \%$, CI $2.51-$ 2.67). The prevalence of insulin-dependent diabetes was $0.069 \%$ (CI $0.059-0.078$ ), and that of non-insulin-dependent diabetes was $2.49 \%$ (CI 2.43-2.54). Males showed a slightly higher prevalence of IDDM than females $(0.080 \%$, CI $0.065-0.094$, vs $0.059 \%$, CI 0.047-0.070) who in turn had a slightly higher prevalence of NIDDM $(2.53 \%$, CI $2.45-2.61$, vs $2.45 \%$, CI 2.37-2.53). In a small number of subjects $(n=115,1.9 \%)$ it was not possible to establish with a sufficient degree of confidence the type of diabetes ("unclassified diabetes").

In both males and females, the prevalence of known diabetes remained below $0.2 \%$ until age 30 years when it progressively increased to a plateau of approximately $10 \%$ in males aged $65-79$ years, and to a peak of $11.5 \%$ in females aged $75-79$ years, and finally declined to $6.6 \%$ in males, and $7.8 \%$ in females older than 84 years (Fig. 1). Diabetes was more frequent in males under age 70 years, while it was more frequent in females after age 75 years.

As expected, IDDM was more frequent in the early decades, while NIDDM occurred more frequently in advanced age (Fig. 2). No significant difference in age-specific prevalence of IDDM was observed be- 
Table 1. Main clinical features of the Verona diabetic cohort on 31 December 1986

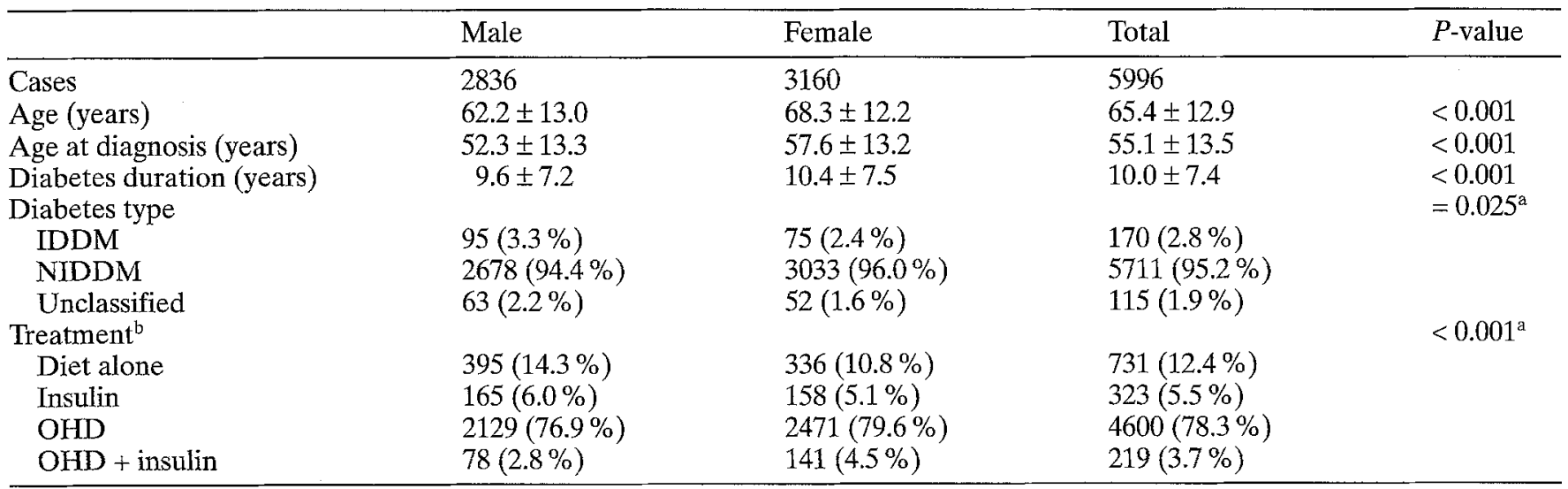

a Refers to the overall variable distribution between sexes

b Therapeutic regimen could not be assessed in 69 men and 54 women. Missing data were neglected when computing percentages

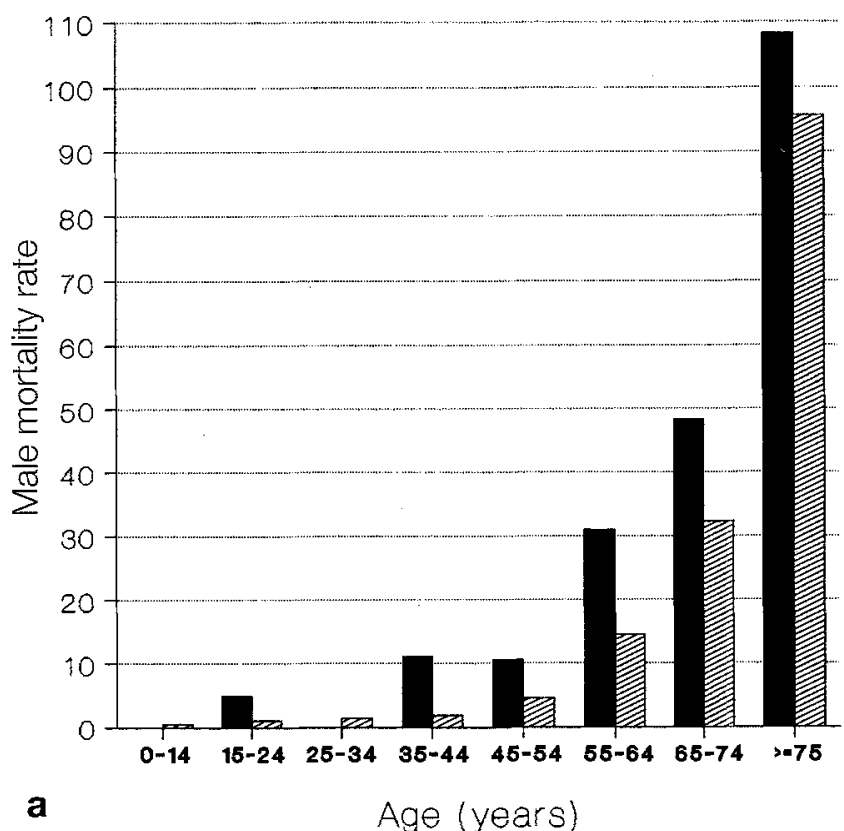

Fig. 3 a, b. Age-specific all-cause mortality rates per 1000 person-years in the Verona diabetic cohort $(\square)$ over the 5-year period (1987-1991), as compared with all cause-mortality rates in the non-diabetic population of the Social Health Unit of Verona (㛭). Panel a male; panel $b$ female

tween males and females, while the pattern of agespecific prevalence of NIDDM in the two sexes paralleled that of overall diabetes.

The main clinical features of the diabetic cohort are summarized in Table 1 . Females, who represented $52.7 \%$ of the cohort, were older, had a later diagnosis and reported a longer duration of diabetes than males. In males the prevalence of IDDM and "unclassified diabetes" was higher than in females, who showed a higher prevalence of NIDDM $(p=0.025)$. Oral hypoglycaemic drugs (OHD) were
Values are given as mean \pm SD for continuous variables and as absolute frequency, with percent frequency in brackets, for categorical variables. The statistical analysis refers to the comparison between sexes; NS Not significant

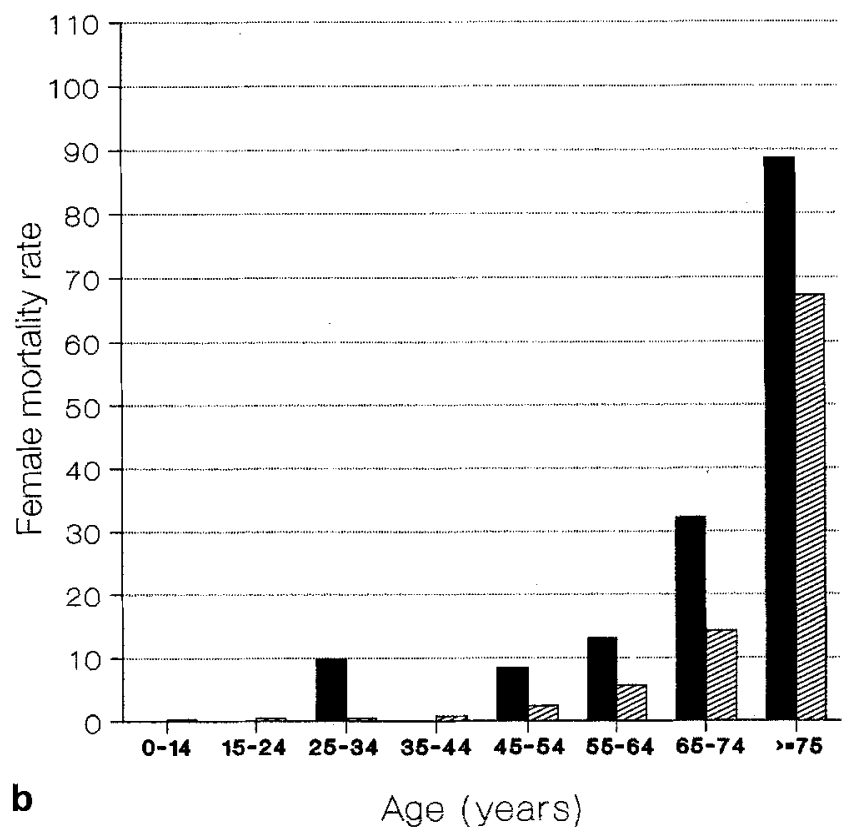

the most common form of treatment in this cohort $(78.3 \%)$. Insulin was used alone in $5.5 \%$ of patients and in association with OHD in $3.7 \%$ of cases. The therapeutic regimen was significantly different in the two sexes $(p<0.001)$. In particular, treatment with diet alone was used more frequently in males, while OHD and OHD plus insulin were used more extensively in females.

Mortality study. By 31 December 1991, 1260 diabetic subjects (592 males and 668 females) out of 5996 had died. The expected number of deaths in the reference population was 863 , giving an overall standardized mortality ratio of 1.46 (CI 1.38-1.54). Figure 3 shows the all-cause mortality rate in the diabetic cohort and in the non-diabetic population over the 5 years of follow-up. At all ages, the death rate of the 
Table 2. Mortality in the Verona diabetic cohort over the 5-year period (1987-1991) as a function of actual age, age at diagnosis and disease duration

\begin{tabular}{|c|c|c|c|c|c|c|}
\hline & & Male & & Female & & Total \\
\hline & $\exp$ & obs/exp $(95 \%$ Cl $)$ & $\exp$ & obs $/ \exp (95 \%$ CI) & $\exp$ & obs/exp $(95 \% \mathrm{CI})$ \\
\hline Total & 420.20 & $1.41(1.30-1.53)$ & 443.10 & $1.51(1.40-1.63)$ & 863.30 & $1.46(1.38-1.54)$ \\
\hline Actual age (3) & ars) & & & & & \\
\hline $0-44$ & 1.28 & $4.69(1.71-10.20)$ & 0.33 & $3.03(0.04-16.86)$ & 1.61 & $4.35(1.74-8.96)$ \\
\hline $45-54$ & 7.71 & $2.33(1.38-3.69)$ & 2.33 & $3.43(1.43-6.77)$ & 10.04 & $2.59(1.69-3.79)$ \\
\hline $55-64$ & 54.83 & $2.13(1.76-2.56)$ & 15.46 & $2.33(1.63-3.22)$ & 70.29 & $2.18(1.85-2.55)$ \\
\hline $65-74$ & 130.18 & $1.50(1.30-1.72)$ & 66.1 & $2.27(1.92-2.66)$ & 196.28 & $1.76(1.58-1.95)$ \\
\hline $\begin{array}{l}\geq 75 \\
\chi^{2} \text { for trend }\end{array}$ & 226.20 & $\begin{array}{l}1.13(1.00-1.28) \\
p<0.001\end{array}$ & 358.88 & $\begin{array}{l}1.32(1.20-1.44) \\
p<0.001\end{array}$ & 585.08 & $\begin{array}{l}1.25(1.16-1.34) \\
p<0.001\end{array}$ \\
\hline Age at diagn & sis (year & & & & & \\
\hline $0-34$ & 5.06 & $2.77(1.51-4.64)$ & 2.13 & $2.35(0.76-5.48)$ & 7.19 & $2.64(1.59-4.13)$ \\
\hline $35-44$ & 24.57 & $1.79(1.30-2.40)$ & 8.69 & $2.65(1.68-3.97)$ & 33.26 & $2.01(1.56-2.56)$ \\
\hline $45-54$ & 86.78 & $1.37(1.14-1.64)$ & 46.34 & $1.79(1.43-2.22)$ & 133.12 & $1.52(1.32-1.74)$ \\
\hline $55-64$ & 127.91 & $1.20(1.01-1.40)$ & 131.82 & $1.27(1.08-1.47)$ & 259.73 & $1.23(1.10-1.37)$ \\
\hline $65-74$ & 96.65 & $1.23(1.02-1.47)$ & 145.49 & $1.34(1.16-1.54)$ & 242.14 & $1.30(1.16-1.45)$ \\
\hline$\geq 75$ & 25.45 & $1.10(0.73-1.59)$ & 51.20 & $1.52(1.20-1.90)$ & 76.65 & $1.38(1.13-1.67)$ \\
\hline$\chi^{2}$ for trend & & $p=0.003$ & & $p=0.041$ & & $p=0.002$ \\
\hline Diabetes dur & tion (yed & & & & & \\
\hline $0-4$ & 104.42 & $1.30(1.09-1.54)$ & 99.63 & $1.18(0.98-1.42)$ & 204.45 & $1.24(1.10-1.41)$ \\
\hline $5-9$ & 82.06 & $1.11(0.89-1.35)$ & 80.32 & $1.51(1.25-1.80)$ & 162.38 & $1.31(1.14-1.49)$ \\
\hline 10-14 & 82.12 & $1.47(1.22-1.76)$ & 84.90 & $1.32(1.09-1.59)$ & 167.02 & $1.40(1.22-1.59)$ \\
\hline $15-19$ & 60.21 & $1.30(1.02-1.62)$ & 80.36 & $1.49(1.24-1.79)$ & 140.57 & $1.41(1.22-1.62)$ \\
\hline$\geq 20$ & 37.63 & $1.36(1.01-1.78)$ & 40.46 & $1.98(1.57-2.46)$ & 78.09 & $1.68(1.40-1.99)$ \\
\hline$\chi^{2}$ for trend & & NS & & $p=0.003$ & & $p=0.007$ \\
\hline
\end{tabular}

The expected number of deaths (exp) and the observed/expected ratios (obs/exp) with $95 \%$ CI between brackets are reported. NS, Not significant

Table 3. Mortality in the Verona diabetic cohort over the 5-year period (1987-1991) as a function of diabetes type and treatment

\begin{tabular}{|c|c|c|c|c|c|c|}
\hline & \multirow[b]{2}{*}{$\exp$} & \multicolumn{2}{|l|}{ Male } & \multicolumn{2}{|l|}{ Female } & Total \\
\hline & & $\overline{\text { obs } / \exp (95 \% \mathrm{CI})}$ & $\exp$ & obs/exp $(95 \%$ CI $)$ & $\exp$ & obs/exp $(95 \%$ CI $)$ \\
\hline Type of diabetes & & & & & & \\
\hline IDDM & 1.11 & $2.70(0.54-7.90)$ & 0.59 & $5.08(1.02-14.86)$ & 1.70 & $3.53(1.29-7.68)$ \\
\hline NIDDM & 411.72 & $1.40(1.29-1.52)$ & 438.81 & $1.48(1.37-1.60)$ & 850.53 & $1.44(1.36-1.53)$ \\
\hline Unclassified & 7.37 & $1.76(0.94-3.02)$ & 3.70 & $3.78(2.07-6.35)$ & 11.07 & $2.44(1.61-3.55)$ \\
\hline Treatment & & & & & & \\
\hline Diet alone & 59.37 & $0.83(0.61-1.09)$ & 43.21 & $0.60(0.39-0.88)$ & 102.58 & $0.73(0.58-0.92)$ \\
\hline Insulin & 10.19 & $2.45(1.59-3.62)$ & 10.47 & $2.67(1.78-3.87)$ & 20.66 & $2.57(1.92-3.36)$ \\
\hline $\mathrm{OHD}$ & 333.11 & $1.43(1.31-1.57)$ & 366.65 & $1.51(1.39-1.65)$ & 699.76 & $1.47(1.39-1.57)$ \\
\hline $\mathrm{OHD}+$ insulin & 9.33 & $2.79(1.82-4.08)$ & 17.54 & $2.57(1.87-3.43)$ & 26.87 & $2.64(2.06-3.33)$ \\
\hline
\end{tabular}

The expected number of deaths and the observed-expected ratios (obs/exp) with $95 \%$ CI between brackets are reported. NS, Not significant

diabetic cohort was higher than that of the non-diabetic population, in both males and females. However, this difference narrowed dramatically in the older ages, particularly in males.

Table 2 reports the observed/expected ratio (obs/ exp) for the whole cohort, as well as in males and females. No significant difference was observed in all males vs all females, but when subjects were divided into age groups, females aged 65-74 years showed obs/exp ratios significantly higher than males, while in other age groups the differences were not substantial. Of note is that in both sexes there was a significant decrease in mortality risk from younger to older age groups. Accordingly, under age 44 years mortality in the diabetic cohort was four times higher than in the non-diabetic population, while over age 75 years it was increased by $25 \%$. Table 2 shows that mortality risk, particularly in males, was inversely related to age at diagnosis and that mortality, in females but not in males, was directly related to duration of diabetes.

The mortality risk was apparently higher, particularly in females, in IDDM than in NIDDM (Table 3). However, due to the limited number of observed and expected deaths in young subjects, the difference was not statistically significant. Further, the therapeutic regimen appeared to be a significant pre- 
dictor of mortality. Pharmacological treatment of diabetes (OHD alone or with insulin, insulin alone) was associated with an excess mortality, while diet treatment seemed to be associated with a mortality risk lower than that in the non-diabetic population (Table 3 ). In patients treated with OHD alone, mortality was increased to a lesser extent than in patients receiving insulin.

\section{Discussion}

The main findings of the Verona Diabetes Study are: 1) an overall prevalence of known diabetes of $2.61 \%$ (CI 2.56-2.67) on 31 December 1986; 2) an overall all-cause SMR of 1.46 (CI 1.38-1.54) in the 5 years of follow-up. This information was obtained from a well-characterized cohort of diabetic subjects living in a well-defined urban area of north-east Italy.

The prevalence study was carried out by using three independent sources of ascertainment: family physicians and paediatricians, the two diabetes clinics of Verona, and the prescription database for antidiabetic drugs and diagnostic and therapeutic devices. A similar methodological approach was adopted in two recent studies carried out in Italy, one in a suburban area near Naples [2], the other carried out in Casale Monferrato, a rural area of north-west Italy [3]. Interestingly, the results of these three surveys were consistent: prevalence of known diabetes was $2.21 \%$ in Casale Monferrato compared to $2.52 \%$ in Naples and $2.61 \%$ in Verona.

When extending the comparison to results obtained in other southern European countries, the great methodological differences among the various surveys must be taken into account. They make comparison difficult and lead to a diabetes prevalence ranging from $1 \%$ to $23 \%$ [1]. In addition to methodology, also demographic and geographic differences could account for the different prevalence rates of known diabetes found in northern Europe [11-14]. However, it is noteworthy that recent data from Finland $[15,16]$ are similar to those in our study, despite these studies being based on diabetes registers.

Prevalence of diabetes increased strikingly after the age of 40 years. Prevalence was higher in males up to age 69 years and in females after age 75 years. This phenomenon has already been described [16] and it has been attributed to a larger excess mortality in men or, perhaps, to other factors, including a later occurrence of NIDDM in females [16].

In agreement with other studies [16], the prevalence of diabetes in Verona decreased after the age of 80 years in both sexes. This phenomenon is difficult to explain. It could be caused by an excess mortality in diabetic patients during the previous decade, but it could also reflect a cohort phenomenon. These people, aged 80-98 years on 31 December
1986 and born between 1888 and 1906, might have experienced a lower incidence of diabetes during their lifetime, as a result of a lower exposure to diabetogenic factors in comparison with subsequent generations. Alternatively, these people could have been subjected to a larger excess mortality when affected by diabetes during their early life $[17,18]$, as a consequence of less advanced medical care.

Prevalence of IDDM in Verona on 31 December 1986 was $0.069 \%$, similar to that found in north-west Italy [3], but lower than that found in Sardinia [19]. Interestingly, in spite of the remarkable difference in the absolute prevalence of IDDM, in both Verona and Sardinia the highest prevalence of this type of diabetes was found in males born in the late 1960s and early 1970s, reflecting a trend observed in other areas [20]. The age-related increase in the prevalence of NIDDM found in Verona is consistent with reports from several areas of the world $[3,6,16,21]$.

It is generally accepted that mortality in diabetes cannot be assessed through the analysis of death certificates, where diabetes is often underreported as the underlying cause of death $[5,6,22,23]$. Reliable information on diabetes-related mortality requires prospective studies of defined cohorts recruited from general population surveys [22]. To our knowledge, our study on diabetes-related mortality is the first study with these characteristics carried out in southern Europe. The size of our study is remarkable, since it included the follow-up of about $26,830 \mathrm{pa}-$ tient-years, the analysis of about 18,000 death certificates, and the tracing of $97.8 \%$ of the initial cohort.

Two studies with similar characteristics have been recently carried out in Scotland [24, 25] and agreed with our finding that diabetic patients have a mortality risk approximately $50 \%$ higher than non-diabetic subjects. Earlier investigations reported a two [26] or threefold [27] increase in mortality risk in diabetes. This discrepancy could reflect an improvement in diabetes prognosis from the 1960s [27], to the 1970s [26] and into the 1980s, when the two Scottish studies $[24,25]$ and the Verona Diabetes Study were carried out.

It is well known that the difference in death rates between diabetic and non-diabetic subjects narrows remarkably with advancing age [24-26, 28], but it has not been established whether in the older age groups diabetes is still associated with an excess mortality $[25,26,29,30]$. Our data suggest that in males and, to a greater extent, in females the excess mortality persists even after age 75 years. For mortality in the middle age, our figures are consistent with those reported by others $[24,31-33]$ and are only slightly lower than those found in Aberdeen [25] and in Gothenburg [34]. Small discrepancies could be explained by the fact that as a reference population in some studies the general population was used, while in other studies the non-diabetic population was 
used. We found the highest obs/exp ratios in younger subjects, most of whom were IDDM patients. Even though our absolute values were somewhat different from those reported by others [17, 24, 25, 35-37], the phenomenon we observed was similar to that described by these authors. However, it should be mentioned that in young age groups the evaluation of mortality risk is hampered by the generally low number of observed and expected deaths. Moreover, the life expectancy in young diabetic patients has dramatically increased over the last 20 years, and this might strongly contribute to differences between recent as compared to earlier studies.

Even though absolute mortality rates were higher in males than in females at all ages, we found that the relative risk of mortality was not significantly higher in males than in females. On the contrary, the obs/exp ratio was slightly, but not significantly, higher in females than in males. However, it should be stated that females were older than males, and this difference in age might have resulted in a relative decrease of obs/exp ratio in females as compared to males. In females aged 65-74 years obs/exp ratio was significantly higher than in males. This result, which is consistent with several data reported by other investigators $[5,22,25,26,38]$, suggests that diabetes reduces, but not abolishes, the female survival advantage seen in the non-diabetic population.

In agreement with the literature, the present study showed that the excess mortality was inversely related to age at diagnosis [22] and directly related to diabetes duration [29].

In our study excess mortality in IDDM was more than double than in NIDDM. This result, although not statistically significant due to the small number of observed and expected deaths in young patients, is consistent with those of other reports [33]. However, the comparison of mortality in IDDM and NIDDM patients could be questionned, due to the large age differences of these subjects.

Among different therapeutic regimens, insulin treatment was associated with the highest mortality risk in our, as well as in previous studies $[27,29,39]$. The influence of other therapeutic regimens on mortality is much more controversial. Treatment with OHD or with diet alone has been associated both with an increased [30,39] or with an unmodified [29] risk of death. In our study, the mortality risk in OHD-treated patients was slightly, but significantly, increased, while in patients treated with diet alone it was decreased as compared to the non-diabetic population. To our knowledge, such a protective effect against mortality occurring in diet-treated patients has not previously been reported. An explanation could be that the assiduous medical care featuring diabetes would result in a beneficial effect on survival when the disease is mild, most probably for the control of associated risk factors. This beneficial ef- fect of assiduous medical care would be overwhelmed when diabetes is more severe and requires a pharmacological treatment.

In conclusion, the Verona Diabetes Study has provided solid information on the prevalence of known diabetes in a typical urban area of north-east Italy, and its frequency of distribution across ages and in both sexes. The mortality follow-up has provided original information on this aspect of diabetes in south Europe, indicating that the disease is associated with an excess mortality. The latter is particularly high in young patients, decreases with age, but is still present in elderly patients. This excess mortality is greater in females than in males, and in patients treated with insulin as compared to other therapeutic regimens. Treatment of diabetes with diet alone was associated with an apparent protective effect on mortality.

Acknowledgements. This work was supported by grants No. 86.01873.56, 87.00374.56, 91.00400.PF40, 92.00337.PF40 and 93.00421.PF40 from the Italian Consiglio Nazionale delle Ricerche (CNR) (INV 953541) and by 1986 to 1994 contributions from the Ministero dell' Università e della Ricerca Scientifica e Tecnologica (MURST).

The authors are grateful to members of the Labour Unions of the family physicians of Verona: Drs. P. Costa, G.Danti of CUMI-AMFUP; F. Ferrari, A. Battaggia of FIMMG; M. Gangemi, M.Agostini of FIMP; G. Corbellini, G. Lombardo of SNAMI; to Dr. L.Bozzini, director of the Pharmaceutic Section of Verona SHU, who provided access to the prescription data source; to Dr. C.Zamboni, director of the Section of Informatics of Verona SHU, Mr. G. Manfrin and Mr. G. Nota, from the same Section; Ms. L.Santi, computer operator; to the Verona Medical Association, for the substantial logistic support in the implementation of the study; to Mrs. M.Longo, for expert secretary assistance.

\section{References}

1. Papoz L (1991) Recent trends in the epidemiology of diabetes mellitus in European and Mediterranean countries. Acta Diabetol 28: 140-142

2. Vaccaro O, Imperatore G, Ferrara A, Palombino R, Riccardi G (1992) Epidemiology of diabetes mellitus in Southern Italy: a case-finding method based on drug prescriptions. J Clin Epidemiol 45: 835-839

3. Bruno G, Bargero G, Vuolo A, Pisu E, Pagano G (1992) A population-based prevalence survey of known diabetes mellitus in Northern Italy based upon multiple independent sources of ascertainment. Diabetologia 35: 851-856

4. World Health Annual Statistics (1986) World Health Organization, Geneva, 1978-1985

5. Fuller JH, Elford J, Goldblatt P, Adelstein AM (1983) Diabetes mortality: new light on an underestimated public health problem. Diabetologia 24: 336-341

6. Ekoè JM (1988) Diabetes mellitus. Aspects of the worldwide epidemiology of diabetes mellitus and its long-term complications. Elsevier Science Publishers (Biomedical Division)

7. National Diabetes Data Group (1979) Classification and diagnosis of diabetes mellitus and other categories of glucose intolerance. Diabetes 28: 1039-1057 
8. Coleman M, Douglas A, Hermon C, Peto J (1986) Cohort study analysis with a Fortran computer program. Int J Epidemiol 15: 134-137

9. Breslow NE, Day NE (1986) Statistical methods in cancer research: the design and analysis of cohort studies. Volume II. IARC Scientific Publications, Lyon, pp 69-72

10. Monson RR (1980) Occupational epidemiology. CRC Press, Boca Raton, Florida

11. Mather HM, Keen H (1985) The Southall diabetes survey: prevalence of known diabetes in Asians and Europeans. BMJ 291: 1081-1084

12. Neil H, Gatling W, Mather HM et al. (1987) The Oxford community diabetes study: evidence for an increase in the prevalence of known diabetes in Great Britain. Diabet Med 4: 539-543

13. Croxson SCM, Burden AC, Bodington M, Botha JL (1990) The prevalence of diabetes in elderly people. Diabet Med 8: $28-31$

14. Toumilehto J, Nissinen A, Kivela SL et al. (1986) Prevalence of diabetes mellitus in elderly men aged 65 to 84 years in eastern and western Finland. Diabetologia 29: $611-615$

15. Eriksson J, Forsen B, Haggblom M, Teppo AM, Groop L (1992) Clinical and metabolic characteristics of type 1 and type 2 diabetes: an epidemiological study from the Narpes community in western Finland. Diabet Med 9: $654-660$

16. Laakso M, Pyörälä K (1985) Age of onset and type of diabetes. Diabetes Care 8: 114-117

17. Dorman JS, LaPorte RE, Kuller LH et al. (1984) The Pittsburgh insulin-dependent diabetes mellitus (IDDM) morbidity and mortality study. Mortality results. Diabetes 33: 271-276

18. Borch-Johnson K, Kreiner S, Deckert T (1986) Mortality of type 1 (insulin-dependent) diabetes mellitus in Denmark: a study of relative mortality in 2930 Danish type 1 diabetic patients diagnosed from 1933 to 1972 . Diabetologia 29: 767-772

19. Songini N, Loche M, Muntoni S et al. (1993) Increasing prevalence of juvenile-onset type 1 (insulin-dependent) diabetes mellitus in Sardinia: the military service approach. Diabetologia 36: 547-552

20. Green A, Andersen PK, Svendsen AJ, Mortensen K (1992) Increasing incidence of early onset type 1 (insulin-dependent) diabetes mellitus: a study of Danish male birth cohorts. Diabetologia 35: 178-182

21. Pozza G, Garancini P, Gallus G (1994) Prevalence and incidence of NIDDM. In: Williams R, Papoz L, Fuller J (eds) Diabetes in Europe. John Libbey London, pp 21-38

22. Panzram G (1987) Mortality and survival in type 2 (non-insulin-dependent) diabetes mellitus. Diabetologia 30: 123131

23. Balkau B, Papoz L (1992) Certification of cause of death in French diabetic patients. J Epidemiol Commun Health 46: $63-65$
24. Waugh NR, Dallas JH, Jung RT, Newton RW (1989) Mortality in a cohort of diabetic patients. Causes and relative risks. Diabetologia 32: 103-104

25. Wong JSK, Pearson DWM, Murchison LE, Williams MJ, Narayan V (1991) Mortality in diabetes mellitus: experience of a geographically defined population. Diabet Med 8: 135-139

26. Panzram G, Zabel-Langhennig R (1981) Prognosis of diabetes mellitus in a geographically defined population. Diabetologia 20: $587-591$

27. Garcia MJ, McNamara PM, Gordon T, Kannel WB (1974) Morbidity and mortality in diabetics in the Framingham population. Sixteen-year follow-up study. Diabetes 23: 105-111

28. Goodkin G (1975) Mortality factors in diabetes. J Occup Med 17: 716-721

29. Kleinman JC, Donahue RP, Harris MI, Finucane FF, Madans JH, Brock DB (1988) Mortality among diabetics in a national sample. Am J Epidemiol 128: 389-401.

30. Stengard JH, Tuomilehto J, Pekkanen J et al. (1992) Diabetes mellitus, impaired glucose tolerance and mortality among elderly men: the Finnish cohorts of the seven countries study. Diabetologia 35: 760-765

31. Stamler J, Vaccaro O, Neaton JD, Wentworth D (1993) Diabetes, other risk factors, and 12-yr cardiovascular mortality for men screened in the multiple risk factor intervention study. Diabetes Care 16: 434-444

32. Morrish NJ, Stevens LK, Head J, Fuller JH, Jarrett RJ, Keen $\mathrm{H}$ (1990) A prospective study of mortality among middle-aged diabetic patients (the London cohort of WHO multinational study of vascular disease in diabetics). I. Causes and death rates. Diabetologia 33: 538-541

33. Head J, Fuller JH (1990) International variations in mortality among diabetic patients: the WHO multinational study of vascular disease in diabetics. Diabetologia 33: 477-481

34. Rosengren A, Welin L, Tsipogianni A, Wilhemsen L (1989) Impact of cardiovascular risk factors on coronary heart disease and mortality among middle-aged diabetic men: a general population study. BMJ 299: 1127-1131

35. Modan M, Karp M, Bauman B, Gordon O, Danon YL, Laron Z (1991) Mortality in Israeli Jewish patients with type 1 (insulin-dependent) diabetes mellitus diagnosed prior 18 years of age: a population based study. Diabetologia 34: $515-520$

36. Hirohata Y, MacMahon B, Root HF (1967) The natural history of diabetes. I. Mortality. Diabetes 16: 875-881

37. Kessler II (1971) Mortality experience of diabetic patients26 year follow-up study. Am J Med 51: 715-724

38. Keil EK, Sutherland SE, Knapp RG et al. (1993) Mortality rates and risk factors for coronary disease in black as compared with white men and women. N Engl J Med 329: 7378

39. Dupree EA, Meyer MB (1980) Role of risk factors in complications of diabetes mellitus. Am J Epidemiol 112: 100112 